\title{
Arte público y memoria. Sistemas de significado"
}

\author{
Arte publikoa eta memoria. Esanahi-sistemak
}

Public Art and Memory. Meaning Systems

\author{
Núria Ricart Ulldemolins \\ Universitat de Barcelona \\ nuriaricartulldemolins@ub.edu \\ https://orcid.org/0000-0002-0510-9473

\section{Jordi Guixé Coromines} \\ EUROM - Fundació Universitat de Barcelona \\ jordiguixe@ub.edu \\ https://orcid.org/0000-0003-3060-764X
}

\section{Resumen}

\begin{abstract}
La re-significación de espacios de memoria es un tema de análisis académico desarrollado por la historiografía, el arte, la arquitectura, el patrimonio, la sociología y las ciencias políticas entre otras disciplinas. El análisis que proponemos parte de una mirada interdisciplinar, aunque interesada de modo específico en los lenguajes del arte y los sistemas de significado en el espacio público. Abordamos la problemática en dos partes: la primera con el desarrollo de cuatro perspectivas conceptuales que nos ayudan a determinar los principales conceptos sobre los que, en un segundo momento, aplicar un modelo experimental en forma de proyecto de intervención.
\end{abstract}

\section{Palabras clave}

Arte público; monumento; memoria; espacio público; re-significación.

\section{Sumario}

1. Objeto. 2. Metodología. 3. Perspectivas. 3.1. Lo nombrado/identificado. Topónimos y nomenclátor. 3.2. Interpelaciones contemporáneas. Sincronías 3.3. Los significantes vacíos, soportes de interpretación. 3.4. Lo construido/conmemorado. Monumentalidad y re-significación. 4. MODELO DE EXPERIMENTACIÓN. DESARTICULAR LAS JERARQUíAS. 4.1. El caso del marqués destronado. BIBLIOGRAFíA.

* La investigación se enmarca en el desarrollo del proyecto HAR2017-84322-P, Arte Público y Memoria. Desarrollos para el programa de intervención en la red de espacios de represión franquista http://ub.edu/publicmem. Y en los resultados de las investigaciones previas llevadas a cabo en el marco del proyecto Public Space's Service System An integrated assessment methodology (PTDC/ECM-URB/2162/2014). Brandão y Brandão, 2018. 


\begin{abstract}
Laburpena. Besteak beste historiografiak, arteak, ondareak, soziologiak eta zientzia politikoek garatutako ikerlan akademiko bihurtu da memori-lekuei esanahi berria emateko prozesua. Proposatzen dugun azterketa diziplina arteko begirada batetik abiatzen da, nahiz eta berariaz interesa izan artearen hizkuntzetan eta espazio publikoko esanahi sistemetan. Problematika bi zatitan landuko dugu: lehena, kontzeptuzko lau ikuspegi garatzea, kontzeptu nagusiak zehazten lagunduko digutenak; bigarren unean, eredu esperimental bat aplikatuko diegu, esku hartzeko proiektu baten bidez.
\end{abstract}

Gako hitzak. Arte publikoa; monumentua; memoria; espazio publikoa; esanahi berria.

\begin{abstract}
Re-signifying" memory spaces is an academic subject analysed by different disciplines: historiography, art, architecture, heritage, sociology, political science, etc. We propose an interdisciplinary perspective, specifically interested in the languages of art and the systems of meaning in public space. The methodology develops a blended approach, divided in two parts: the first one, analyses four conceptual perspectives focused on public space and meaning; the second one, tries to apply all the ideas in an experimental model.
\end{abstract}

Keywords. Public art; monument; memory; public space; "re-signifying».

\section{Objeto}

El objeto del siguiente análisis es el vínculo intrínseco entre arte público y memoria, en un marco conceptual más amplio que es el del espacio público y sus propios sistemas de significados.

Entendemos el concepto de espacio público como un objeto de estudio complejo y poliédrico; en el que destacan múltiples facetas, entre las principales: las lógicas de poder y representación; la tipología urbana; y los usos cotidianos (en forma de actividad, abuso, desuso, etc. ${ }^{1}$. En un contexto social y económicamente convulso, como en el que nos encontramos en la actualidad, el espacio público adquiere gran centralidad: de pronto, objetos significantes que apenas nos hablaban, como eran algunos monumentos decimonónicos, hoy adquieren una enorme relevancia. Vuelven a interpelar nuestros valores y sistemas, vuelven a ser catalizadores de debates inconclusos.

En este contexto, nos interesa atender al papel del arte público contemporáneo como modo de reflexión, visibilidad, incluso rechazo de discursos y debates, en un proceso de re-semantización ${ }^{2}$ tensa del espacio basada en códigos y dinámicas de simbolización, reivindicación y legitimación por parte de los poderes públicos y de la propia ciudadanía.

Dicho de otro modo, asistimos a la expresión pública constante por parte de sectores sociales que participan y se apropian de sus espacios públicos en una tensión entre legitimidades distintas (fig. 1).

1 Lefebvre, 1972; Borja y Muxí, 2001; Brandão, 2005; Brandão y Brandão, 2018; Ricart y Remesar, 2013; Ricart, 2016.

2 Debray, 1999. 




Figura 1: Vandalismo contra la instalación Franco Victòria República, en el Centro de Cultura y Memoria del Born, epicentro simbólico del independentismo catalán. Barcelona, 2016. Fuente: Núria Ricart.

Tensiones que en ocasiones afectan de modo preponderante a los elementos simbólicos de dicho espacio, convirtiéndose incluso en objeto de discordia. La respuesta social a elementos patrimoniales o instalaciones de arte contemporáneo -ligados a acontecimientos de escala local o internacional-muestra la preminencia política del espacio y la capacidad simbólica del arte para la transmisión de mensajes y valores. A través de la acción, la apropiación, la provocación, la ironía..., el arte público despliega hoy códigos tipológicos, formales y temporales propios de la contemporaneidad; y con ellos vuelve a ser leído como símbolo de comunicación y transmisión de valores y contravalores de una sociedad convulsa -y por tanto reactiva-, en que la memoria es a la vez objeto de investigación y debate ideológico.

\section{Metodología}

En este contexto nos proponemos atender a los campos y modos de acción del arte público en su dimensión memoria, y por tanto significado; lo que nos lleva a la observación de sus lógicas en los modos de construcción urbana. El ejer- 
cicio resulta del abordaje de pruebas indiciarias, de fragmentos incompletos. La ciudad no es un libro abierto, pero si contiene siǵnos que pueden ser reconocidos (semiótica); y que ligan con significados que pueden ser comprendidos, incluso compartidos (semántica). Partimos de la siguiente pregunta: ¿es posible «hacer pensable el pasaje entre lo semiótico y lo semántico» en la ciudad? ${ }^{3}$

Proponemos abordar esta problemática en dos fases. Primero, proponemos cuatro perspectivas que nos ayuden a identificar las principales dimensiones del objeto de análisis. Existen diversos sistemas de transmisión de significados en la ciudad, siendo los más reconocidos los sistemas de información y comunicación. Sin menoscabar su enorme influencia en los mapas cognitivos en lo que respecta a la regulación de usos, en este apartado nos proponemos reflexionar en torno a otros posibles sistemas en los que observamos elementos constitutivos de enorme eficacia discursiva, y que desde nuestro punto de vista se pueden organizar con base a lógicas de construcción urbana, como son:

- Lo nombrado/identificado. Topónimos y nomenclátor

- Interpelaciones contemporáneas. Sincronías

- Los significantes vacíos, soportes de interpretación

- Lo construido/conmemorado. Monumentalidad y re-significación.

En segundo lugar, presentaremos una propuesta de intervención como modelo experimental, en el que aplicamos las perspectivas desarrolladas desde una estrateǵia clara de re-significación. Aquí proponemos el uso de los lenǵuajes del arte para dar respuesta a una problemática compleja que creemos debe ser abordada interdisciplinarmente.

\section{Perspectivas}

\subsection{Lo nombrado/identificado. Topónimos y nomenclátor}

Nombrar significa identificar memorias y perspectivas ideológicas que en ocasiones entran en conflicto siendo objeto de discordia política y social en procesos de legitimación/deslegitimación de valores y significados.

En este sentido la toponimia se configura como una cartografía cognitiva ${ }^{4}$ local compleja, que desde sus primeras regulaciones en el siǵlo XIX desarrolla una de las formas de gestión, organización y legibilidad de lo urbano con más vínculos con lo social ${ }^{5}$, y por tanto constituye el reflejo de los grandes cambios,

3 Agamben, 2010, pp. 64, 82.

4 Jameson, 1991.

5 Vidal et al., 2005. 
transformaciones políticas y culturales a nivel histórico. Cartografía basada en dos planos distintos: uno de larǵa duración, enormemente estable, basado en: a) la tipología del lugar (hardware): calle, plaza, plazoleta, avenida, puente, camino, y b) la dimensión morfológica y de memoria (calle Mayor, plaza de la Fuente...).

Y un segundo plano, conmemorativo, mucho más inestable y sometido a fuertes tensiones en cuanto a procesos de legitimación de signnificados y valores culturales, históricos y políticos. A modo de ejemplo de esta dinámica, observamos el caso del cambio de nomenclátor de la calle Almirall Cervera, una de las más importantes de la Barceloneta (Barcelona), que desde 2018 es rebautizada con el nombre de Pepe Rubianes. El primero fue almirante en la Guerra guerra de Independencia de Cuba; el segundo, fallecido más recientemente, era un queridísimo actor catalán de oriǵen gallego. Los debates intercambiados en la prensa alrededor de esta modificación mantuvieron un pulso ideológico sesgádo a favor y en contra de los valores asociados a los personajes objeto de polémica.

La violencia que significa nombrar las cosas con un concepto que, per se, excluye el resto de ideas sobre el mundo ${ }^{6}$ se suma, en este caso, al uso del poder y sus atributos ideológicos, para la configuración de mapas mentales enraizados en valores temporales que, vistos en perspectiva, pueden ser conflictuales a diversos niveles, incluyendo los vacíos dejados.

Efectivamente, una lectura en perspectiva de género sobre el estudio del nomenclátor en Cataluña publicado en 2008 sitúa a las mujeres referentes en posiciones casi inapreciables. La escritora Mercè Rodoreda (la mujer con más calles del estudio), se halla en el número 29 de la lista dedicada a nombres propios encabezada por ilustres médicos, políticos, profesores... En menos de una década, el mismo Instituto que publicara el trabajo, crea ahora el «Nomenclátor de Cataluña de calles con nombre de mujer». Se trata de una herramienta digital que pretende «dar visibilidad a las aportaciones que hacen las mujeres en nuestra sociedad, y que muchas veces quedan invisibilizadas, o no son suficientemente reconocidas» ${ }^{7}$.

Hace 170 años, la propuesta de Víctor Balaguer para los nombres de las calles del Ensanche de la «nueva Barcelona», se justificaba, también, en «remediar un olvido». El «olvido en que por mala ventura han caído ciertas empresas ǵloriosas, ciertos nombres célebres, que lo han sido, y serán siempre de gloria para Cataluña ${ }^{8}$. Así nacía el nomenclátor más importante de la ciudad, enraizado cultural e ideológicamente en la historia de Cataluña.

\footnotetext{
6 Žižek, 2013.

7 Parella, 2008.

8 Fabre y Huertas, 1982.
} 


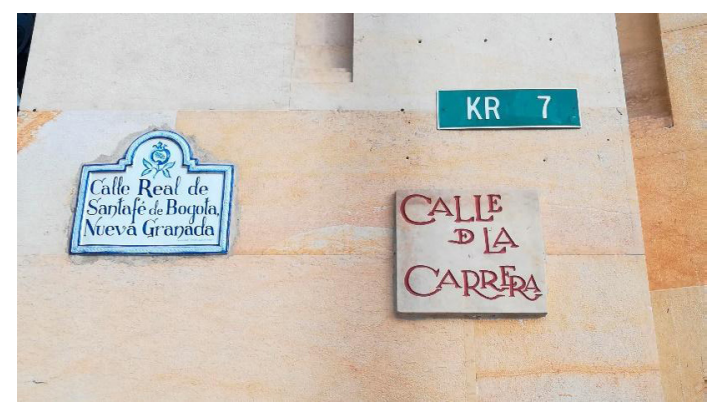

Figura 2: Carrera 7, Bogotá (2019). Fuente: Núria Ricart.

Los procesos de significación a través del nomenclátor parecen abordar programas basados en el vacío y la falta como mecanismo para el ejercicio de nuevas visibilidades que, a su vez, determinarán otros vacíos, otras faltas (fig. 2).

En las reivindicaciones actuales ligadas a la visibilidad de género y memoria subyace una crítica de los modelos que han constituido las diversas capas de toponimia de la ciudad y que han invisibilizado las figuras referenciales femeninas (figs. 3 y 4). Dichas reivindicaciones han hecho uso de lenguajes «artivistas» contemporáneos, y la fuerza de estos movimientos transversales ha tenido consecuencias en las políticas municipales sobre el nomenclátor. En ciudades consolidadas como Barcelona, son los pequeños pasajes y los jardines interiores del ensanche los que llevan, desde hace unos años, nombres de mujeres ${ }^{9}$.



Figura 3: Intervención artística temporal reivindicativa sobre el nomenclátor (Sant Martí de Provençals, BarceIona, 2016). Fuente: Comisión Memoria y Género.

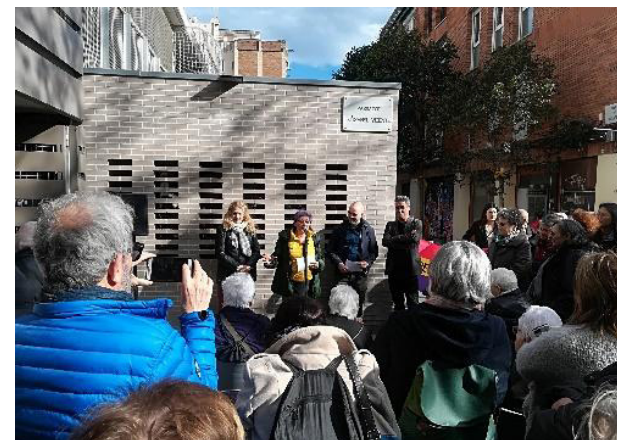

Figura 4: Inauguración del Pasaje de Isabel Vicente, 12/4/2018. Promueve Plataforma Futur Monumento Cárcel de Mujeres de les Corts, EUROM, Distrito de Gracia-Ayuntamiento de Barcelona. Fuente: Núria Ricart.

9 La justificación es que la ciudad no crece territorialmente y por tanto no cuenta con grandes avenidas, plazas o calles que poder nombrar. 
Los vínculos de las mujeres con los lugares que las conmemoran son directos en algunos casos; pero, en otros, los nombres forman parte de los imaǵinarios genealógicos feministas, de enorme relevancia cultural, pero sin dimensión memorial con el territorio. La implantación de políticas de equilibrio de género en el nomenclátor ha generado en ocasiones pérdidas de la memoria del territorio que pudieran estar representadas en su toponimia.

\subsection{Interpelaciones contemporáneas. Sincronías}

Podemos vincular el debate dicotómico sobre legitimación/deslegitimación de topónimos a la idea expresada por Gabi Dolff-Bonekämper, quien sugiere que el valor de la discordia (streitwert) es positivo cuando es capaz de articular -mediante objetos polémicos como son los monumentos, los nombres de las calles, etc.- debates políticos inconclusos. Dolff-Bonekämper entiende el conflicto en torno a la conservación, o no, de determinadas estructuras como un valor en sí, partiendo de que, en democracia, la deliberación, el desacuerdo e incluso la postergación de la toma de decisión son parte del proceso político. Este proceso permite a la opinión pública posicionarse frente al pasado, pese a la incomodidad que pueda generar ${ }^{10}$.

Walter Benjamin denomina en su Libro de los Pasajes a estos elementos (acordes o discordantes) «indicios»o «imágenes», señalando que

todo presente está determinado por aquellas imágenes que le son sincrónicas: todo «ahora» es el ahora de una determinada cognoscibilidad [...]. No es que el pasado arroje su luz sobre el presente o el presente su luz sobre el pasado, sino que imagen es aquello en lo cual lo que ha sido se une como un relámpago con el ahora en una constelación ${ }^{11}$.

En otras palabras, los indicios o imágenes (calle Almirall Cervera, la estatua de un dictador, la escultura de Marco Aurelio en el Campidoǵlio...) son elementos del pasado que interpelan a distintas generaciones de modos diversos, generando nuevas miradas sobre ellos mismos. Son significaciones yuxtapuestas en diversas contemporaneidades. Desde su filosofía poética, Zambrano lo expresa del siguiente modo: «El presente es siempre fragmento, torso incompleto. El pasado completa esa imaǵen mutilada. La dibuja más entera e inteligible» ${ }^{12}$. Y del pasado,

\footnotetext{
${ }^{10}$ Dolff-Bonekämper, 2003.

11 Agamben, 2010, pp. 96-97.

12 Zambrano, 2014, p. 58.
} 
no todo nos vale, escogemos el indicio o imagen que puede completar nuestra interpretación del mundo.

Dichas sincronías generan dinámicas muy potentes de re-significación de la ciudad, aunque -advierte Agamben- «el objeto histórico, entonces, nunca está dado de modo neutral, sino que siempre está acompañado por un índice o por una signatura, que lo constituye como imagen y determina y condiciona temporalmente su legibilidad» ${ }^{13}$.

La fotografía de Pérez de Rozas hecha en el Día de la Mercè de 1944 en la Cárcel de Mujeres de les Corts (Barcelona), en plena posǵuerra, puede ilustrar esta lógica (figs. 5 y 6). La fotografía fue tomada en el despacho del director como ejercicio propagandístico del régimen franquista, que de forma magnánima escenografiaba la puesta en libertad de una presa.

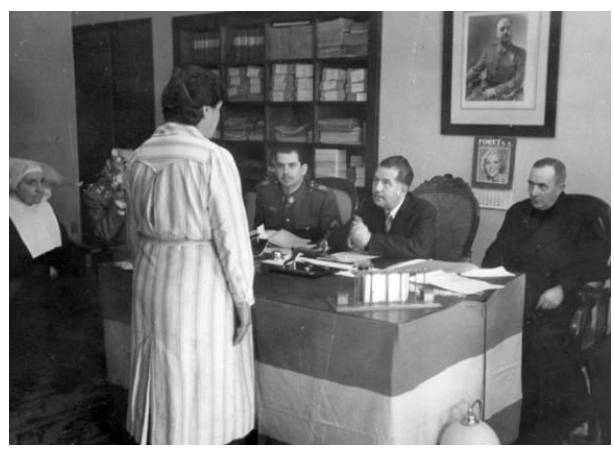

Figura 5: Día de la Mercè, Cárcel de Mujeres de les Corts, 1944, Barcelona, Pérez de Rozas. Fuente: Archivo Fotográfico de Barcelona.

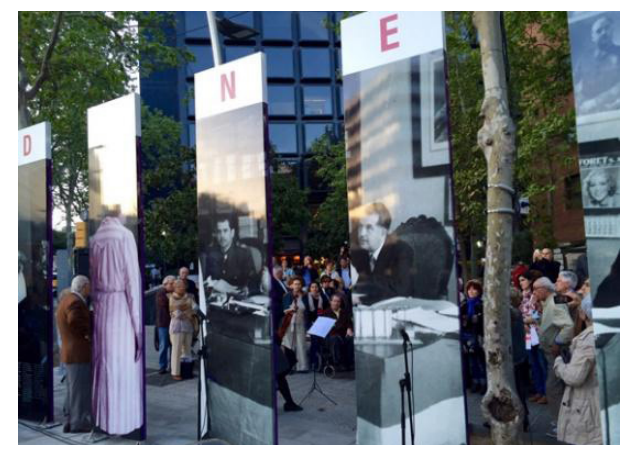

Figura 6: 14 de abril de 2015, Espacio de memoria Cárcel de Mujeres de les Corts, Barcelona (Acto conmemorativo organizado por la Plataforma Futur Monument Presó de Dones de les Corts). Fuente: Plataforma Futur Monument Presó de Dones de les Corts.

En 2014, esta misma fotografía sirve, en el proceso ciudadano de recuperación de la memoria «Futur Monument Presó de Dones de les Corts» ${ }^{14}$, para marcar el antiguo territorio de la cárcel con unos tótems escultóricos e informativos. La lectura contemporánea de esta imagen nos interpela y aproxima al conocimiento de las estructuras y modos de la dictadura franquista y, en especial, a la posición de la mujer fuera de los estamentos de poder del ejército, la tecnocracia

13 Agamben, 2010, p. 98.

${ }_{14}$ Proceso ciudadano de recuperación de la memoria de la cárcel de mujeres de les Corts (Barcelona) y de reivindicación de un monumento. Más información en: https://presodedones.wordpress. com/. 
y la iǵlesia católica. En la actualidad y bajo el prisma de Benjamin, la fotografía corresponde a un auténtico «índice» para una sincronía en la que una imagen del pasado adquiere una lectura contemporánea situándose en un nuevo contexto, el espacio público, y aportando una nueva capa de significado sobre el lugar y su memoria en cuanto a la represión contra las mujeres.

\subsection{Los significantes vacíos, soportes de interpretación}

Claude Lévi-Strauss desarrolla en 1950 una teoría respecto del exceso de siǵnificantes en relación a los significados que puedan definirlos. En su Introduction to the Work of Marcel Mauss y a propósito del concepto de maná escribe:

siempre y en cualquier lugar, este tipo de nociones representan un valor indeterminado de significación, en sí mismo vacío de contenido y por tanto susceptible de recibir cualquier significado ${ }^{15}$.

Estamos ante una lógica que antepone el sistema de interpretación -basado en la dinámica de lo contingente- al propio sistema de significados -como analogías, paradigmas, arquetipos, genealogías...- y que en su aplicación a lo urbano nos lleva a preguntarnos si acaso existen en la ciudad infraestructuras, paisajes, monumentos, barrios, lugares... que trasciendan un solo significado, y queden expuestos a la interpretación como «significantes libres o flotantes, en sí mismos vacíos de sentido [...], operando como exigencia de una significación infinita que ningún significado puede colmar» ${ }^{16}$.

La evolución del lenguaje del arte con la aparición del abstraccionismo en el espacio público de la ciudad desde el periodo de entreguerras, pero sobre todo desde los años 50 del siglo $\mathrm{xx}$, incorpora esta lógica sin maquillaje alguno: «he aquí un objeto sin significado», cuya definición se halla exclusivamente en la interpretación del espectador ${ }^{17}$.

¿Acaso existen otros objetos en la ciudad que, del mismo modo que el arte público abstracto, se hallan abiertos a la constante interpretación, nunca colmados por uno u otro significado? O mejor: ¿Acaso existe algún elemento urbano, alguna calle, plaza, monumento, objeto de mobiliario, jardín... que no esté sujeto a la constante reinterpretación social y subjetividad individual?

\footnotetext{
${ }^{15}$ Lévi-Strauss, 1987, pp. 55-56.

${ }_{16}$ Agamben, 2010, p. 104.

17 Eco, 1984.
} 


\subsection{Lo construido/conmemorado. Monumentalidad y re-significación}

La lógica de los procesos de monumentalización (que puede obedecer a voluntades programáticas más o menos ideologizadas) es uno de los modos de transmisión de significados más desarrollado históricamente.

$\mathrm{Su}$ capacidad comunicativa es, en teoría, enorme; de hecho, en todas nuestras ciudades y pueblos existen espacios y objetos artísticos y/o arquitectónicos especialmente simbólicos para la ciudadanía; lugares con carácter para aǵlutinar las demandas y reivindicaciones conmemorativas, políticas y/o festivas de momentos históricos diversos que se re-significan generacionalmente (fig. 7).

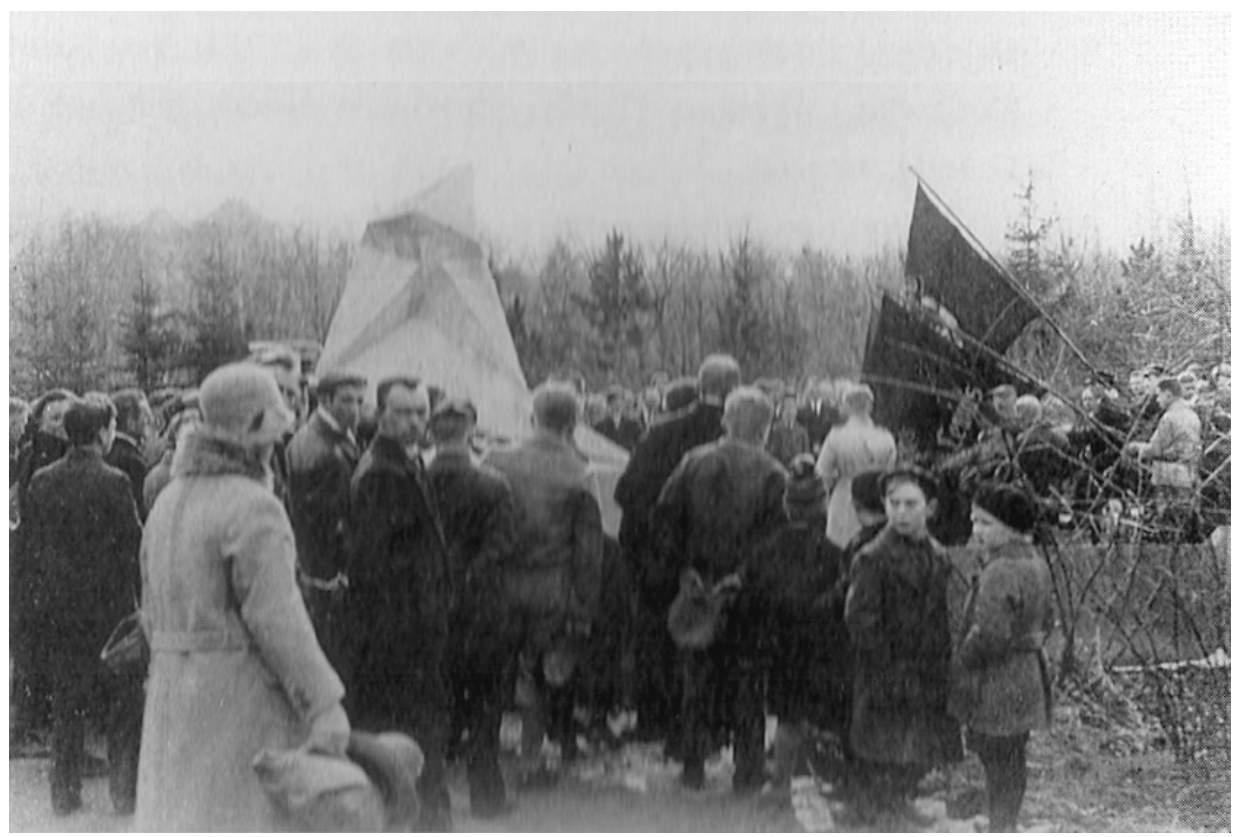

Figura 7: Margenfallenen Denkmal, Walter Gropius. Ofrenda popular, 1925. Fuente: Bergeijk, 2004.

Según Lecea, el monumento tiene en el modelo clásico dos funciones esenciales, la de «embellecimiento y significación» ${ }^{18}$. Opera como un artefacto urbano para la transmisión de hechos históricos socialmente significativos en un doble sentido temporal: manteniendo en la memoria hechos del pasado; pero también

18 Lecea, 2006, p. 15. 
proyectando dicha memoria hacia el futuro. Como explica Debray, el monumento es, en su sentido semiótico, una "carta ensobrada debidamente dirigida desde una época a la siguiente» ${ }^{19}$, y por tanto de él destaca el valor de durabilidad. Se distingue además de otros constructos artísticos por su integración en la trama de la ciudad, y su definición tipológica en la composición territorial ${ }^{20}$.

En palabras de Bohigas, su valor fundamental es el de permanencia en frente de

las azarosas vías de transformación física y social en la ciudad. Esta calidad de permanencia lo hace aglutinador y representante de ciertos aspectos de la identidad colectiva y del grupo social que lo rodea. [...] La permanencia, la identidad visualizada, se convierte, pues, en el factor más trascendental del monumento desde el punto de vista urbanístico, superando incluso la pura función de recuerdo del personaje o el evento histórico que quería rememorar [...]. Por ello, hay que ampliar el concepto de monumento y hay que entender este como todo lo que da significado permanente a una unidad urbana, desde la escultura que preside y aglutina, hasta la arquitectura que adopta un carácter representativo y, sobre todo, aquel espacio público que se carǵa de significaciones. Por ello, «monumentalizar la ciudad» significa organizarla de manera que se subrayen los signos de la identidad colectiva, en los que se apoya la conciencia urbana de esta colectividad ${ }^{21}$

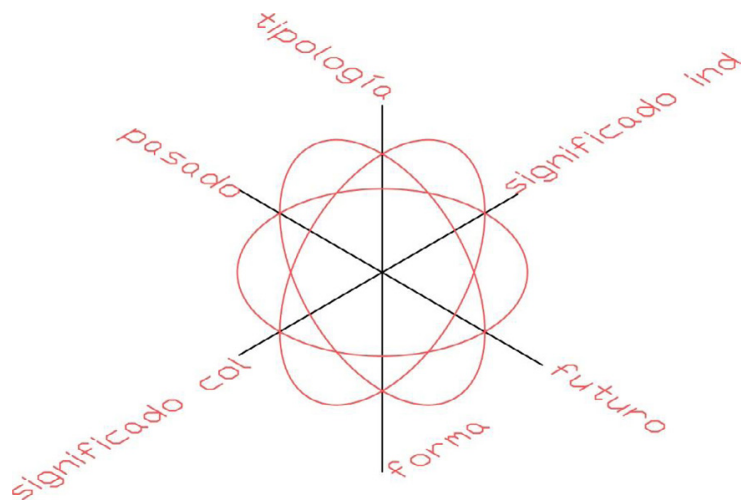

Figura 8: Esquema identificando las coordenadas que configuran los parámetros del arte público y el monumento. Coordenada Tiempo; Tipología / Forma; Significado. Elaborado por Núria Ricart.

\footnotetext{
19 Debray, 1999, p. 30.

${ }^{20}$ Pöete, 2015 [1929].

${ }^{21}$ Bohiǵas, 1985, p. 148.
} 
Los códigos artísticos y arquitectónicos desplegados en el larǵo proceso de monumentalización -desde las primeras construcciones funerarias paleolíticas ${ }^{22}$ hasta los countermonuments de finales del siglo $\mathrm{XX}$ - evolucionan superando límites de orden conceptual en tres dimensiones: la temporal; la formal-tipológica, y la de significación ${ }^{23}$ (fiǵ. 8). Una compleja sintaxis con base a la cual se articulan diversos modelos desarrollados desde el renacimiento (Giambologna, Cellini, Ammanati, Landini...), el barroco (Poussin, Bernini, Borromini, Tuby...), y profusamente explotados en el modelo monumental decimonónico, mediante el cual se expresan algunos de los códigos simbólicos y de representación de la clase burguesa y de la sociedad industrial ${ }^{24}$. Este modelo se impone en el espacio público de pequeñas y grandes ciudades a partir del siǵlo XIX, en un periodo caracterizado por la eclosión de la escultura monumental, que corre en paralelo al crecimiento urbano en forma de ensanches y a la regeneración de núcleos antiguos. La facilidad de reproducción de formas a través de nuevos materiales y tecnologías como la fundición aplicados en el mobiliario y la escultura pública, se suma al renovado interés por el diseño y la organización de la estructura urbana, abriendo una etapa muy prolífica en la cualificación y conmemoración del espacio público ${ }^{25}$.

Concebido bajo premisas de tipo urbanístico y arquitectónico relativamente estrictas, comúnmente el monumento «clásico» se compone de un obelisco u elemento columnario que genera un hito en el paisaje. Asimismo, hallamos otros tipos, con figuras o grupos escultóricos sobre basamento arquitectónico (pedestal). En numerosas ocasiones las obras se sitúan en emplazamientos urbanos como cruces, paseos, plazas, jardines, etc., dependiendo de la preminencia del personaje o hecho conmemorado; su función urbana viene determinada por su tipo monumental (hito urbano en cruces de vías; escenografía en entornos ajardinados; arco como frontispicio o entrada...). Pero su definición formal, incluso su estilo, acoge una gran diversidad de posibilidades en relación a los avances tecnológicos y a los gustos.

En cuanto a su función conmemorativa, ésta es imprescindible en el modelo monumental clásico, aunque a lo largo del tiempo puede adquirir o adaptarse a nuevos significados. El monumento por tanto es capaz de adoptar soluciones formales diversas, y también adoptar significados distintos a través del tiempo. En contraposición, su tipología -su función urbana- es mucho más estable y duradera $^{26}$.

\footnotetext{
${ }^{22}$ Mumford, 1966, p. 13.

${ }^{23}$ Ricart, 2018.

${ }^{24}$ Curtis, 1999.

${ }^{25}$ Remesar, 2016.

26 Pöete, 2015 [1929].
} 



Figuras 9-12. De izquierda a derecha, de arriba a abajo: Inauguración del Monumento a Pi i Margall, 1934. En la cúspide vemos la escultura de Viladomat dedicada a la República. Fuente: Barcelona Atracción, 1936; 1 de abril de 1947, Día de la Victoria. La tipología monumental no ha cambiado pero sí sus elementos escultóricos y simbólicos. La escultura de Viladomat fue retirada en 1939 y sustituida en la base por la escultura de Marès dedicada a la victoria franquista. Fuente: Archivo Fotográfico de Barcelona; Base del monumento vacío tras la retirada de la escultura de La Victoria, el 30 de enero de 2011. Desde 1981 está grabado el escudo de la casa real. Fuente: Núria Ricart; Monumento a Espriu, 2013, y El obelisco al fondo. Fuente: Núria Ricart. 
Podemos decir por tanto que los significados transitan entre los elementos tangibles de lo que permanece y estructura territorialmente la ciudad, como son los monumentos pero también los paisajes, el patrimonio, el espacio público... Más allá del objeto conmemorativo original, en ellos co-existen significados diversos, que se desplieǵan tanto a nivel temporal, a lo largo de distintos momentos históricos; como a nivel grupal, por parte de diversos grupos sociales que ven en el lugar/símbolo una representación de sus valores colectivos. En este sentido Valera añade:

un espacio será simbólicamente más potente, no necesariamente cuantos más individuos compartan unos mismos significados, emociones o afectos referidos a ese espacio, sino cuanto más claramente estén definidos estos significados, emociones o afectos por el grupo social en relación con ese espacio ${ }^{27}$.

Los significados pueden ser muy diversos, incluso contradictorios, dando lugar a debates sobre ausencias o interpelaciones. Este es el caso del obelisco situado en el centro de Barcelona desde 1934, en la intersección de las dos vías más importantes de la ciudad: Diagonal y Paseo de Gracia (figs. 9-12). La tipología y función urbanística del monumento no se ha visto modificada desde que fue construido en 1934, pero sí su objeto de conmemoración, que ha transitado por diversos siǵnificados políticos contradictorios a lo largo del tiempo; hasta el punto que la función conmemorativa original no tiene mayor valor que el conjunto de significaciones con los que le han ido dotando los hechos históricos que lo han modificado, los cuales han supuesto también alteraciones formales, aunque no sustantivas en relación a su tipología urbana que siempre se ha mantenido como obelisco en cruce de calles.

¿Es tal vez este caso un buen ejemplo para abordar lo que Debray identifica como la crisis del monumento-mensaje entendido éste como aquella carta ensobrada de una época para la siguiente?

Para su superación, el autor apuesta por «re-semantizar» el espacio urbano, dotándolo de nuevos mensajes comunicativos basados en un lenguaje compartido, para lo cual es imprescindible «revitalizar el espacio público y el sentido cívico» de la contemporaneidad, cuyos valores y códigos difieren de los desarrollados en décadas anteriores -ni que decir tiene del modelo monumental decimonónico-. Debray acaba reflexionando sobre la importancia de inventar nuevos modelos artísticos para «re-semantizar» el espacio público ${ }^{28}$.

En España, los debates en torno a la re-significación de monumentos de la dictadura, como el Valle de los Caídos en el Escorial (Madrid) o el Monumento

\footnotetext{
27 Valera, 1993.
}

${ }^{28}$ Debray, 1999. 
a los Caídos de la Cruzada en Navarra, son de enorme actualidad. ¿Cómo se resignifica un monumento? Ha sido una de las preguntas más recurrentes en la prensa, coincidiendo con la exhumación del dictador de su tumba en el Valle de los Caídos. Y viendo con este gesto por tanto la oportunidad de transformar la esencia de un lugar negro de nuestra historia. Los desarrollos legislativos y las experiencias analizadas, especialmente en Chile y Argentina, nos llevan a plantear una hipótesis metodológica para la re-significación de un monumento, un mausoleo, un espacio de memoria. Entendiendo que re-significar no es barnizar, ni abrillantar; es transformar en profundidad los significados desde una perspectiva crítica mediante la articulación de nuevos vínculos sociales con el lugar.

Proponemos una hipótesis programática para la re-signnificación de espacios de memoria:

A, primero investigar, luego actuar:

Significados

1) Significados originales

- Significados alternativos a lo largo del tiempo

- Acciones que han activado o desactivado significados

2) Iconología

- Símbolos-piedra (originales y modificaciones)

3) Usos, actores, gestión

- Actores y gestión de usos, desusos, abusos...

Para el desarrollo de un programa interdisciplinar de re-significación basado en la estrategia de desarticular las jerarquías (simbólicas y de uso)

Existen luǵares paradiǵmáticos re-signnificados como es el propio Campo de exterminio de Auschwitz-Birkenau, en Polonia. Hoy en día un lugar completamente transformado para la transmisión mediante la conservación del vestigio y la explicación pedagógica in situ. El patrimonio construido, pero también el testimonio, la fotografía, el objeto, el texto y la cartografía explican algunos de los episodios ocurridos de modo sobrio y a la vez expresivo.

El lugar memorial, al final de las vías del tren, tiene una historia singular muy poco conocida (figs. 13-16).

En 1957 se organiza un concurso internacional cuyo objeto es el diseño de un monumento en memoria de las víctimas del nazismo en el Campo de AuschwitzBirkenau. Los promotores, una orǵanización internacional de supervivientes del campo de concentración con base en Viena en cooperación con la Unión Internacional de Arquitectos. Así se crea el Auschwitz Memorial Comittee, el presidente del cual es Henry Moore. La primera selección se hace en base a 426 proyectos presentados por 600 escultores y arquitectos de 36 países. Siete proyectos son escogidos para la segunda fase del concurso, presentada el mes de noviembre de 1958 en las oficinas de la UNESCO en París. 
Uno de los siete proyectos es «The Slab» de Oskar Hansen, arquitecto polaco. Se trata del primer «contra-monumento» proyectado, lo cual nos sitúa ante una obra conceptual que supera el lenguaje puramente abstracto. La matriz conceptual del proyecto determina que el memorial es el propio campo y que no hace falta crear ningún elemento exprofeso para su conmemoración. En él se plantea determinar un espacio longitudinal como lugar de reflexión, memoria y contemplación. Este lugar será, en esta primera fase del concurso, las propias vías del tren y el área final definida por los crematorios.

Hansen gana en una segunda vuelta el concurso con una redefinición del proyecto. En esta segunda etapa decide negar la lógica de acceso longitudinal (propia de los días en que funcionaba el dramático ferrocarril que conducía miles de personas al matadero), a través de la implantación de un nuevo recorrido diagonal: «The Road». Espacio de gran anchura libre para andar, diseñado para la conmemoración, la memoria, la reflexión y para el uso social activo y participativo. Lugar desde el que observar el campo, sumido a las inclemencias del tiempo, que será el encargado de convertir barracones y crematorios en ruinas para la vegetación.

El énfasis de Hansen en la acción humana deriva en lo que denomina The Open Form, idea que impregna todo su trabajo posterior, donde se plantea que es el diseño del espacio -la forma y concepción de la obra pública- el que facilita la acción libre del visitante o transeúnte; el que posibilita la actitud participativa a nivel individual y/o colectivo; y finalmente, el que promueve la aparición de usos emergentes a través de la actitud libre de la ciudadanía. Para Hansen, The Open Form constituye la base física donde construir la obra en forma de acontecimiento: «The art of events». Lo cual significa valorar la transformación del entorno a través de la acción; valorar al fin y al cabo el tiempo, y no exclusivamente el espacio como estructura atemporal.

Aun así, las víctimas no se identifican con un proyecto tan abstracto y conceptual, lejos de la expresión clásica del recuerdo y la conmemoración. «No fuimos asesinados ni torturados en lo abstracto» dirá un exprisionero del campo viendo el proyecto. Recordemos que estamos en 1958. También, al parecer, hay presiones (así lo recuerda alguna de las biografías de Henry Moore) de tipo político. El campo de Auschwitz-Birkenau, en Polonia, estaba situado bajo la influencia de la Unión Soviética, desde donde se observaban con reticencia propuestas formales abstractas propias del polo occidental en plena guerra fría.

Finalmente, el diseño ganador en 1959 es fruto de un trabajo de colaboración entre tres proyectos de tres equipos diferentes: The Road de Hansen, y el de dos equipos italianos más. Este híbrido, también alterado respecto del diseño previsto por razones económicas y políticas, se inaugura en 1967 entre las dos cámaras de gas y los crematorios II y III. 

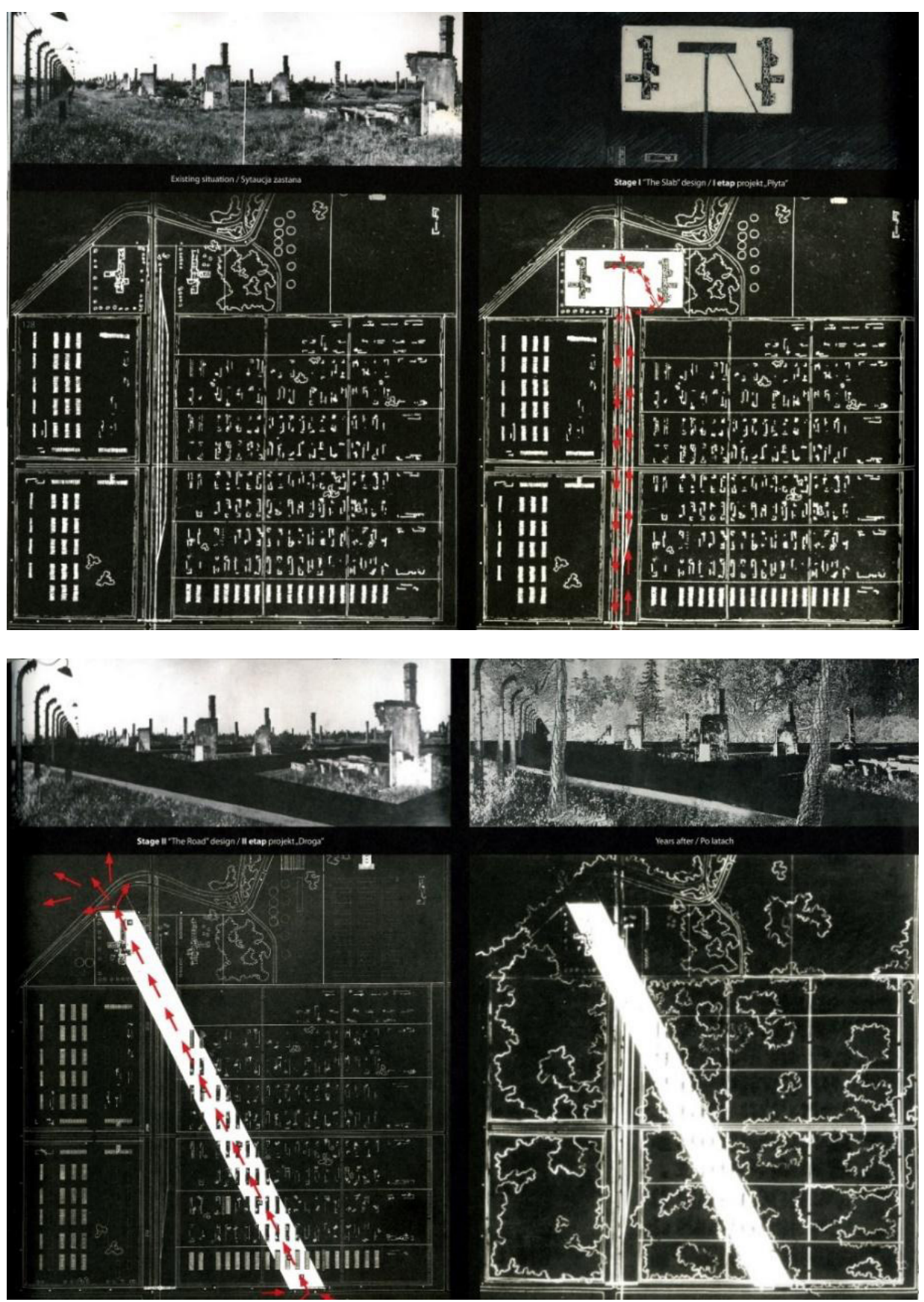

Figuras 13 y 14: Oskar Hansen, "The Slab» (1 ${ }^{\text {a }}$ fase del concurso); "The Road» (proyecto gandor). International Competition for Auschwitz-Birkenau Monument, 1958. Fuente: Hansen, 2005. 

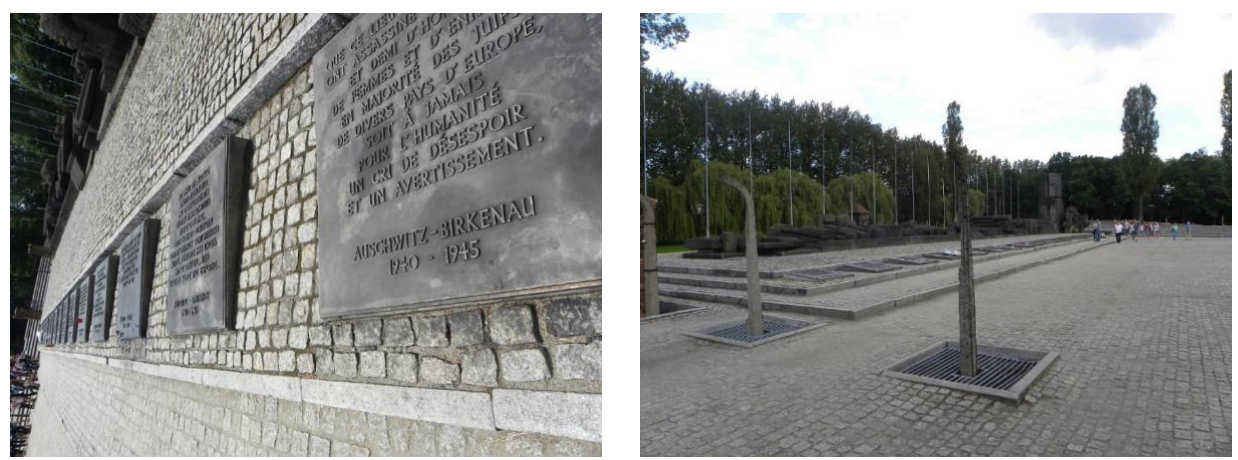

Figuras 15 y 16: Vista del Monumento en Auschwitz-Birkenau, proyecto de síntesis entre diversos equipos, 2015. Fuente: Núria Ricart.

Este ejemplo, paradigmático en muchos sentidos, nos sirve para atender a una de las cuestiones expuestas desde el inicio.

A lo larǵo de todo el siglo xx, perdemos los códigóos del modelo monumental decimonónico. Aquel que regía en la lógica de creación de ciudad y significación de hechos simbólicos. A partir de aquí, otros códigos deben redificarse en un proceso constante de cambio, cuando el desarrollo de las vanguardias artísticas y su obsesión por los avances en cuestiones formales sumen al arte en un diálogo endogámico que ahonda en los problemas de comunicación entre proyecto artístico y sociedad.

¿En qué estrategias se apoyan los lenguajes de la nueva monumentalidad -a partir de las primeras vanguardias- para dar respuesta a dos demandas simultáneas -y a su vez relativamente antagónicas- como son: 1) desarrollar la función conmemorativa, basada en demandas sociales apremiantes tras las grandes guerras del siǵlo XX e inicios del XXI; y 2) ahondar en los lenguajes abstraccionistas como campo de desarrollo propio del arte del siǵlo Xx?

En el fondo de esta cuestión hallamos de nuevo la cuestión de inicio: ¿es posible hacer pensable el pasaje entre lo semiótico (signos que pueden ser reconocidos) y lo semántico (compartidos) en la ciudad?

En los monumentos a las víctimas, situados según J. E. Young «en la intersección entre arte público y memoria política» ${ }^{29}$, observamos el despliegue precoz de los lenguajes abstraccionistas y conceptuales de mayor radicalidad, aunque plenamente interesados en el ejercicio de la conmemoración y, en consecuencia,

29 Young, 2000, p. 93. 
con aportes proyectuales novedosos que se han convertido en modelos de pensar en arte público y hacer ciudad para el siǵlo XXI.

1) «The art of events». La convergencia entre arte público y acción de la ciudadanía, potenciando la inmersión plena del espectador como parte de la obra artística ${ }^{30}$.

2) La obra ambiental. Que se abre al territorio y todos sus componentes. Ya no estamos ante la tipología cerrada y centrípeta; al contrario, el territorio forma parte de la obra ${ }^{31}$.

3) El nombre. La identificación verbal del nombre de la víctima o su contexto como elemento esencial de significación y vínculo con la sociedad.

\section{Modelo de experimentación. Desarticular las jerarquías}

Hasta aquí hemos tratado alǵunas perspectivas en cuanto a sistemas de siǵnificado en el espacio público. Hemos abordado el modo de significación más directo, no exento de conflicto: el nomenclátor. Hemos introducido el concepto de índice o imagen como sincronía y fuente de reinterpretación del presente tras una mirada renovada hacia el pasado. Hemos destacado el hecho subjetivo de la interpretación en el contexto comunicativo de la ciudad. Hemos ahondado en el campo de la monumentalidad como uno de los ejercicios de transmisión de la memoria, y por tanto de significado, más potentes. El análisis de la estructura del monumento y sus planos de intersección han concluido en la idea de la existencia de diversas dimensiones, unas muy duraderas, otras mucho más cambiantes. Finalmente hemos hecho un alto en el concepto de re-semantización o re-significación; de enorme contemporaneidad.

Una conclusión de este ejercicio especulativo es que los lenguajes del arte nos sirven para generar o re-significar espacios de urbanidad en el espacio público en los cruces de las coordenadas entre el territorio y la significación para mantener y nutrir la transmisión del pasado, o proyectar ideas de futuro en relación a las culturas en las que nos desarrollamos social e individualmente. Y esta conclusión ha sido el objeto del proyecto de intervención que presentamos a continuación, entendido como modelo de experimentación de las perspectivas conceptuales desarrolladas en el apartado anterior.

\footnotetext{
${ }^{30}$ Hansen, 2005.

${ }^{31}$ Maderuelo, 1990, 1994.
} 


\subsection{El caso del marqués destronado}

Los paradigmas sobre el espacio público se activan o desactivan en base a la difusión de proyectos institucionales, pero también en base a rumores mediáticos y movimientos ciudadanos de contestación. En los últimos años, pero sobre todo a partir del movimiento social global conocido como \#BlackLivesMatter, se ha abierto en canal el debate sobre el homenaje público a los prohombres de un sistema económico basado en el esclavismo y el colonialismo, el cual subyace a las estructuras neoliberales actuales, eminentemente racistas y clasistas.

Los casos sobre los monumentos de destacados líderes del pasado que ganaron fortunas con la trata de esclavos y con explotaciones coloniales están a la orden del día. La memoria esclavista y colonial es una memoria incómoda para los gobiernos y los Estados. A menudo se trata de piezas eclécticas que conviven con nuestras sociedades democráticas, en la mayoría de los casos sin más pena que gloria. Pero la activación social, política y mediática alrededor de estas figuras históricas y sus monumentos ha despertado un debate más necesario que nunca cuando nos referimos a los valores que subyacen a las democracias liberales en la actualidad, sustentadas simbólica y económicamente en poderes del pasado.

Se trata de estructuras jerárquicas que aún nos interpelan porque nos hablan de nuestras propias injusticias. Por eso surge la pulsión iconoclasta y derribamos estatuas, porque sus símbolos aún estructuran nuestro imaǵinario social, cultural y económico. Son esas sincronías -aludiendo al concepto desarrollado anteriormente- que interpelan el presente desde el pasado, constituyendo un índice simbólico a re-significar.

En Barcelona, como en centenares de otras ciudades monumentalizadas por el paradiǵma de la metrópolis colonial, asistimos en la actualidad a este debate, centrado principalmente en dos casos fraǵrantes, el monumento a Colón y el monumento a López y López.

Si los entendemos como lugares de memoria en sí, podemos aplicar la hipótesis programática, presentada anteriormente, para el desarrollo de un proceso de re-significación. ¿Podrían ser estos objetos simbólicos re-significados y reconvertirse en lugares abiertos al debate crítico, no ya como símbolos cerrados de un sistema de valores caduco e insolidario, sino como sincronías de un pasado y por tanto latentes y abiertos a la interpretación, con una mirada renovada?

Es necesario conocer antes de intervenir; abrir debates y actuar. Debates públicos multicanal como congresos académicos, concursos de ideas, informaciones y opiniones periodísticas, procesos ciudadanos de participación... Debates en los que quepan los lenguajes interdisciplinares, pero con un objetivo clave de re-significación: desarticular las jerarquías. 
Como caso paradiǵmático de la memoria incómoda de Barcelona, presentamos el monumento a Antonio López y López, marqués de Comillas ${ }^{32}$, ubicado desde 1884 en la céntrica Plaza de Antonio López. Fue uno de los hombres más influyentes de la España de la seguunda mitad del siǵlo XIX, con intereses económicos diversificados entre los transportes, los tabacos la inmobiliaria y la banca. Existen pruebas de que parte de su fortuna procede del comercio de esclavos en Cuba.

Después de un debate profundo y una valiente política pública de memoria por parte del Ayuntamiento de Barcelona ${ }^{33}$, éste retira la estatua al depósito municipal, pero mantiene el pedestal, repleto de significados simbióticos entre colonialismo y renaixença ${ }^{34}$. En este contexto, el Observatorio Europeo de Memorias y la Facultad de Bellas Artes, ambos de la Universidad de Barcelona, abordamos el conflicto de memorias del lugar desde cuatro ámbitos diversos:

1. Estudio histórico del monumento y biográfico del personaje.

2. Proceso de participación con entidades del barrio, Ayuntamiento y expertos.

3. Trabajo de análisis del espacio público, escultórico y del entorno de la plaza que también lleva el nombre -todavía- de Antonio López.

4. Proyecto de ideas y propuesta física y simbólica del espacio, la plaza y el monumento.

La idea clave del proyecto es invertir el significado del monumento transformando la situación jerárquica de sus figuras y posibilitar de este modo una lectura inversa del objeto simbólico oriǵinal. Por tanto, las premisas del proyecto son:

1. La actuación debe interpelar al ciudadano/na, y promover la reflexión sobre la condición y consecuencias nefastas de la esclavitud y el colonialismo.

2. Se deben abordar tres aspectos de modo interdependiente: uno, el nomenclátor, promoviendo la modificación de «Plaza Antonio López» mediante un proceso ciudadano de debate y participación pública. A este respecto, es importante paliar el déficit de género en el nomenclátor de la ciudad y conmemorar el movimiento abolicionista; dos, la estatua, actualmente ubicada en el depósito municipal, ha de ser resituada en el espacio bajo otros parámetros formales; y tres, el pedestal, vacío en su cúspide pero repleto de simbología original.

${ }^{32}$ Lecea, Grandas y Remesar, 2009

${ }_{33}$ Cabe citar que por primera vez el Ayuntamiento de Barcelona creó un Comisionado de Memoria Democrática (2015-2020) que abordó y siǵue abordando temas pendientes que estaban en cajones olvidados, sobre nuestro pasado reciente y la relación de la ciudad, su espacio y su ciudadanía con los símbolos históricos y memoriales.

${ }^{34}$ Movimiento cultural desarrollado a finales del siǵlo XIX a partir del reconocimiento y promoción de la lengua y cultura catalana por parte de la burguesía. 
3. Se plantea concebir un proyecto crítico y basado en la acción y la re-interpretación permanente. Dinamizar ese nuevo lugar de memoria mediante acciones temporales pero cíclicas.

El proyecto de arte público y diseño urbano propuesto y publicado en distintos foros se basa en la idea de destronar al marqués, de-jerarquizando su estatua, ahora hundida en el subsuelo de la plaza, inundada por agua del mar mediterráneo. Planteamos devolver al marqués al mar, el mismo mar de donde tantos beneficios sacó, traficando y comerciando con tabacos, con azúcares, con arte y... con seres humanos. Para ello lo hundimos en una fosa al nivel del mar -nivel freático del antiguo puerto de Barcelona-. Una fosa de cristal para que tanto el Sr. López como la ciudadanía podamos reflexionar en qué podemos reflejar nuestras acciones pasadas o presentes. No es aleccionador, pero sí ejemplar.

El pedestal, repleto de símbolos elocuentes de la relevancia del personaje, se mantiene como fuente de información del pasado. Entre estos símbolos, hallamos una cita del poema «La Atlántida», de Jacint Verdaguer, se dice que escrito en uno de los barcos del marqués. Se trata de una cita en catalán ubicada en el pedestal en 1952.



Figura 17: Proyecto L'Atlàntida, 2019. Jordi Guixé (Observatorio Europeo de Memorias) y Núria Ricart (Facultad de Bellas Artes, UB) ${ }^{35}$.

${ }^{35}$ El proyecto es accesible a través del European Observatory on Memories: https://europeanmemories.net/activities/atlantida/ [consultado en julio de 2020]. 
La Atlántida vuelve a resonar en el nuevo monumento, ahora con otra cita que podría estar inscrita en el pavimento junto a la fosa, al lado del marqués:

Per dar-li en lo sepulcre del mar immensa llosa, un gros penyal fa caure-hi que estava primparat, muntanya sens rabasses, que, en terra ja lent nosa, d'esquitx i bruit dins l'aigua remou la tempestat.

(Jacint Verdaguer, L'Atlàntida $)^{36}$.

Y encima de la peana cada año un concurso de creación artística, gestionado por el Ayuntamiento/Observatorio Europeo de Memorias, con el objeto de profundizar en el tema de la memoria colonial y esclavista, así como en sus modos de transmisión en el espacio público. Este ciclo podría tomar como referencia el evento The Fourth Plinth, que ubica de modo temporal (cada uno o dos años) una obra de arte contemporáneo en uno de los cuatro pedestales -vacío desde su construcción- de Trafalgar Square (Londres).

Este proyecto no se ha podido llevar a cabo, pero la propuesta sigue en pie. Todo requiere un proceso, porque la memoria es debate, proceso, transgresión y conflicto. En todo caso, creemos que las acciones sobre estos u otros monumentos deben ir más allá del derribo, pueden ser catalizadores que promuevan la reflexión y el debate, desde la valentía de acción y la política pública con la interacción interdisciplinar entre profesionales y con la sociedad.

\section{Bibliografía}

Agamben, Giorgio, Signatura rerum. Sobre el método, Barcelona, Anagrama, 2010.

Bergeijk, Herman van, «The März-Monument of Gropius and the concept of Folding», en Herman van Bergeijk y Klaus-Jürgen Winkler, Das Märsgefallenen-Denkmal, Weimar, Bauhaus-Universität, 2004.

Bohigas, Oriol, Reconstrucció de Barcelona, Barcelona, Edicions 62, 1985.

Borja, Jordi, y Zaida Muxí, L'espai públic: ciutat i ciutadania, Barcelona, Diputació de Barcelona, 2001.

Brandâo, Pedro, «Ética e profissoés no designn urbano. Convicçâo, responsabilidade e interdisciplinaridade. Traços da identidad profissional no desenho da cidade», tesis doctoral dirigida por el Dr. Antonio Remesar Belloch, Departamento de Escultura, Facultad de Bellas Artes, Universidad de Barcelona, 2005.

36 «Para darle en el sepulcro del mar inmensa losa, / un gran peñón, enhiesto, hace caer / montaña sin cepas, que en la tierra lenta estorba, / de salpicadura y ruido en el aǵua remueve la tempestad». 
Brandão, Anna, y Pedro Brandão (coords.), Common places. Guide for the assessment and interpretation of public space, Lisboa, IST-ID, Associação do Instituto Superior Técnico para a Investigação e Desenvolvimento, 2018 (E-book: http:// psss.tecnico.ulisboa.pt/en/psss-method/).

Curtis, Penelope, Sculpture 1900-1945, Oxford-New York, Oxford University Press, 1999, cap. II.

Debray, Regis, «Trace, Forme, Message», Les Cahiers de médialogie, 7, 1999, pp. 27-44.

Dolff-Bonekämper, Gabi, «Le Forum de la Culture à Berlin, Monument d'histoire contemporaine», en Maria Gravari-Barbas y Sylvie Guichard-Anguis (eds.), Regards croisés sur le patrimoine dans le monde à l'aube du XXI siècle, París, Presses Universitaires Paris-Sorbonne, 2003, pp. 277-285.

Eco, Umberto, Obra abierta, Barcelona, Planeta-Agostini, 1984.

Fabre, Jaume, y Josep M. Huertas, Carrers de Barcelona, Barcelona, Edhasa, 1982.

Hansen, Oskar, Towards Open Form, EU, Fundacja Galerii Foksal, 2005.

Jameson, Frederic, Postmodernismo o la lógica cultural del capitalismo tardío, Barcelona, Paidós, 1991.

Lecea, Ignasi de, «Esculturas y espacio público en la ciudad de Barcelona», en Iǵnasi de Lecea «In memoriam» on the waterfront, nr 8 april, 2006, http://www.ub.edu/ escult/Water/index.htm [consultado en febrero de 2009].

Lecea, Ignasi de, Carme Grandas y Antoni Remesar, Art públic de Barcelona, Barcelona, Ajuntament de Barcelona/Ámbit, 2009. www.ben.cat/artpublic.

Lefebvre, Henry, Le droit à la ville, París, Éditions Anthropos, 1972.

Lévi-Strauss, Claude, Introduction to the work of Marcel Mauss, London, Routledge and Kegan Paul, 1987.

Maderuelo, Javier, El espacio raptado. Interferencias entre arquitectura y escultura, Madrid, Mondadori, 1990.

Maderuelo, Javier, La pérdida del pedestal, Madrid, Círculo de Bellas Artes, 1994.

Mumford, Lewis, La ciudad en la historia. Sus orígenes, transformaciones y perspectivas, Buenos Aires, Ed. Infinito, 1966.

Nomenclàtor de Catalunya de carrers amb nom de dona, Institut Català de la Dona/Institut Cartogràfic i Geològic de Catalunya, 2014, http://dones.gencat.cat/ca/ambits/sensibilitzacio/nomenclator_carrers_dones [consultado en marzo de 2020].

Parella, Miquel, «Els noms de carrers i places de Catalunya», Institut Cartogràfic i Geològic de Catalunya, 2008, http://www.icge.cat/es/content/download/47998/330133/ version/1/file/Els\%20noms\%20de\%20carrers\%20i\%20places\%20de\%20Catalunya. pdf [consultado en mayo de 2019].

Pöete, Marcel, Introducción al urbanismo. Evolución de las ciudades. Lecciones de antigüedad, Oviedo, KRK Ediciones, 2015 [1929].

Remesar, Antoni, "Arte público. Retos y oportunidades (I). La emergencia de nuevos lenguajes», On the W@terfront, 41, 1, 2016,pp. 7-41.

Ricart, Núria (ed.), Public Space and Memory, Barcelona, Publicacions Universitat de Barcelona, 2016.

Ricart, Núria, «Monumento», en Ricard Vinyes (ed.), Diccionario de la memoria colectiva, Barcelona, Gedisa, 2018, pp. 317-320. 
Ricart, Núria, y Antoni Remesar, «Reflexiones sobre el espacio público/Thoughts on public space», On the w@terfront, 25, 2013, pp. 5-35, https://raco.cat/index.php/ Waterfront/article/view/263776 [consultado el 14/10/2020].

Valera, Sergí, El significado social del espacio. Estudio de la identidad social y los aspectos simbólicos del espacio urbano desde la Psicología Ambiental, libro académico no publicado, 1993, www.ub.edu/escult/valera/valera.pdf [consultado en noviembre de 2018].

Vidal, Tomeu et al., «Toponimia y espacio público: un análisis de caso», en José Romay Martínez y Ricardo García Mira (eds.), Psicología social y problemas sociales. Vol. 5. Psicología ambiental, comunitaria y de la educación, Barcelona, Biblioteca nueva, 2005, pp. 81-86.

Young, James E., At Memory's Edge. After-Images of the Holocaust in Contemporary Art and Architecture, New Haven and London, Yale University Press, 2000.

Zambrano, María, El exilio como patria, Barcelona, Anthropos, 2014.

Žižek, Slavoj, Sobre la violencia. Seis reflexiones marginales, Barcelona, Austral, 2013. 
